\title{
Processing Characteristics Exploration of Metal Based Diamond Wheel of WEDM Dressing and Truing
}

\author{
Han-Ming Chow ${ }^{1}$, Lieh-Dai Yang ${ }^{2,}$, Yan-Cherng Lin ${ }^{1}$, Jung-Chou Hung ${ }^{3}$, Yao-Zhong Gu ${ }^{4}$ \\ ${ }^{1}$ Department of Mechanical Engineering, Nan Kai University of Technology, Nantou, Taiwan \\ ${ }^{2}$ Department of Industrial Management, Nan Kai University of Technology, Nantou, Taiwan \\ ${ }^{3}$ Department of Mechanical and Computer-Aided Engineering, Feng Chia University, Taichung, Taiwan \\ ${ }^{4}$ Institute of Mechanical Engineering, National Kaohsiung University of Applied Sciences, Kaohsiung, Taiwan
}

Email address:

hmchow@nkut.edu.tw (Han-Ming Chow),t215@nkut.edu.tw (Lieh-Dai Yang), ycline@nkut.edu.tw (Yan-Cherng Lin), hungjc@fcu.edu.tw (Jung-Chou Hung), q2129705@yahoo.com.tw (Yao-Zhong Gu)

${ }^{*}$ Corresponding author

\section{To cite this article:}

Han-Ming Chow, Lieh-Dai Yang, Yan-Cherng Lin, Jung-Chou Hung, Yao-Zhong Gu. Processing Characteristics Exploration of Metal Based Diamond Wheel of WEDM Dressing and Truing. International Journal of Materials Science and Applications. Vol. 5, No. 6, 2016 , pp. $290-296$. doi: 10.11648/j.ijmsa.20160506.19

Received: September 26, 2016; Accepted: November 4, 2016; Published: November 10, 2016

\begin{abstract}
This study aims to conduct experiments to explore metal based diamond wheel dressing and truing using developed wire electrical discharge (WEDM). The experimental outputs were analyzed to evaluate the effects of machining parameters on machining removal rate (MRR) and abrasive protrusion during dressing and truing caused by WEDM. During experiments, the wear and compensation issues could be overcome induced by the traditional EDM to improve the efficiency and precision as the WEDM was adopted. The experimental results showed as expected that the wire discharge grinding wheel dressing will lead the processing base not offset. In Taguchi experiment the maximum contribution was current and pulse time, large diameter grinding wheel to remove the highest rate of $11.78 \mathrm{~mm} 3 / \mathrm{min}$, while maximum protrusion amount only 33.12 $\mu \mathrm{m}$, can reach the theoretical maximum protrusion amount.
\end{abstract}

Keywords: Medal Based Diamond Wheel, Wedm, Dressing and Truing, Taguchi Method

\section{Introduction}

In order to obtain high performance grinding, wheel dressing is very important and timely. Metal matrix diamond grinding wheel during complex profile shaping, conventional trimming method is time-consuming, not easy to trim and to obtain high dimensional accuracy. Therefore, it does not meet the demand and also limiting the development of applications in industries [1]. Non-traditional methods such as laser trimming method is expensive, and the laser thermal effect will destroy the diamond abrasive grains $[2,3]$. In recent years, the development of the electrolysis amendments with good quality, high efficiency and a wide range of applications, but can only do wheel dressing, cannot do truing and seriously corroded machine. It must be used and compatible with special anti-corrosion electrolyte $[4,5]$. The EDM can conduct contour-shaping, abrasive dressing, that is, high-precision trimming and adjusting the geometry of different discharge parameters to control the amount of grains protrusion [5-6]. Past, wire electrical discharge machining method for metal-based diamond dressing, the dressing process and processing liquid spray stroke would cause vibrations of copper. This is a major cause that cannot meet the precision requirements of the dressing. Therefore, this study attempts to use removable mechanism of precision ceramic guide pulley copper wire to overcome wire vibration problems in the discharge process and machining fluid jetting, and the mechanism integrated is placed on CNC grinders where $\mathrm{CNC}$ program controlled by mobile precision ceramic guide wheel can quickly make precise and complex contours shaping and sharpening. Therefore, it is important to explore and optimize the design parameters on the discharge metal grinding wheel dressing and sharpening experiment to get the optimal combination of processing parameters. 


\section{Experimental Method}

\subsection{System Design}

Figure 1 shows the scheme of traditional wire EDM diagram with metal-based diamond dressing and truing. Dressing work was conducted on copper between two guide wheels, the distance between the guide wheel caused copper easy to produce tremble and bending deformation by force during dressing process, thereby affecting dressed geometric tolerances. Figure 2 shows the schematic modified wire electrical discharge machining of diamond grinding wheel dressing. Precision ceramic guide pulley was designed a copper trench which the copper wire could be secured to the guide wheel into the groove, and never causing discharge machining fluid jetting and arising tremble, effectively raising the dressing and truing process stability, and thus achieve a higher precision dressing. This study designed a mechanism to contain the simple detachable DC power supply controller which can be placed in $\mathrm{CNC}$ surface grinders, use $\mathrm{CNC}$ surface grinders program control to reach the metal base diamond grinding wheel to do precision dressing and truing online.

Brass wire feed line by line mechanism continues to send and solve traditional dressing EDM electrode consumption and compensation. Brass wire electrode guided by precision ceramic guide wheel will effectively reduce the wire discharge dress tremble traditional problems. Precision ceramic guide pulley, DC power controller and CCD wire measurement and surface grinder integrated monitoring system diagram shown in Figure 3, three-axis servo motor control was taken in order to achieve precise control of trajectory and dressing machining position.
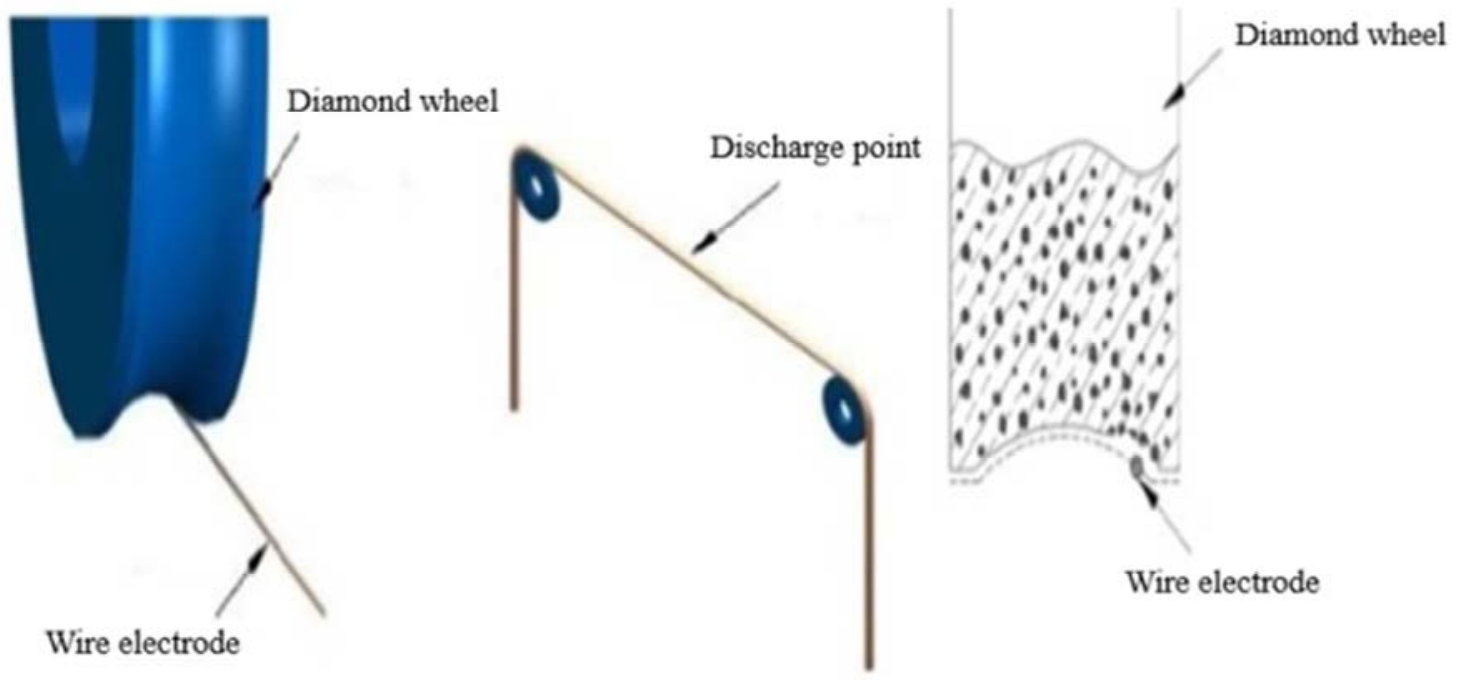

Figure 1. Traditional wire EDM schematic diamond grinding wheel dressing.
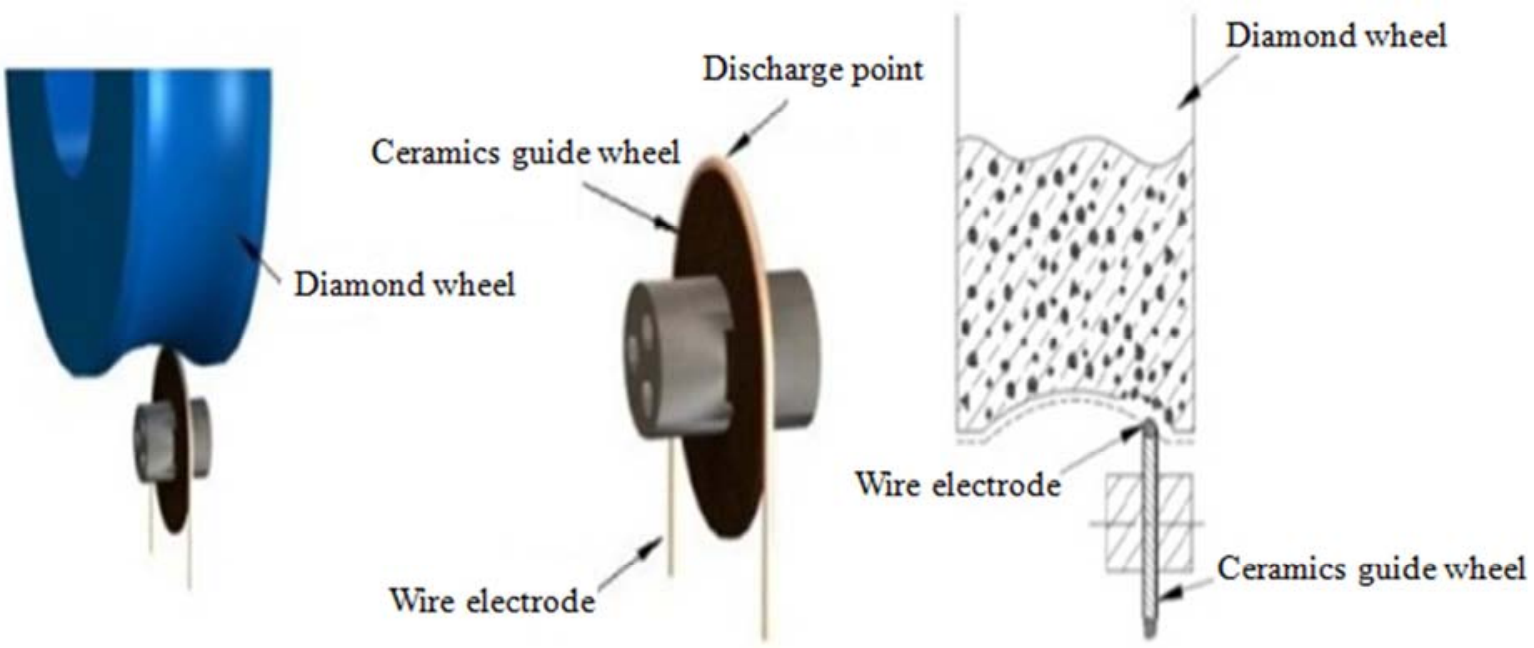

Figure 2. Modified wire EDM dressing diamond grinding wheel schematic. 


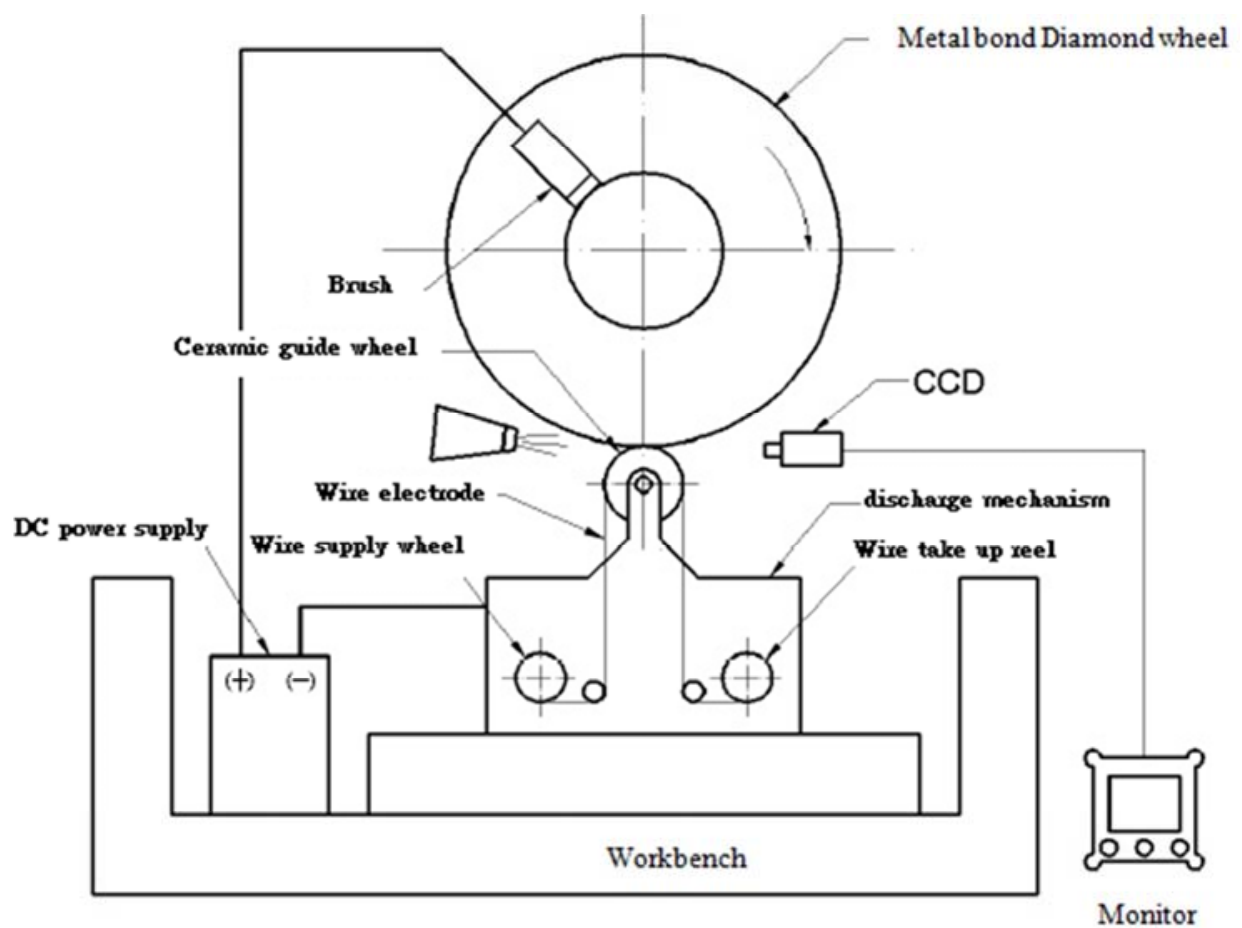

Figure 3. Precision ceramic guide pulley, DC power controller and CCD on line measurement and monitoring system.

In order to obtain a high grinding, timeliness of wheel dressing is very important, but for having a complex contour shaping, in a conventional manner not only time-consuming, difficult to repair and can neither obtain high dimensional accuracy. In addition to the traditional high cost of laser truing, the thermal effect on the diamond abrasive could be damaged. It is easy to configure removable wire mechanism, which was placed on a high-precision surface grinder. To use a modified line precision ceramic guide wheel could improve the efficiency of wire electrode discharge machining. Experimental procedure is shown in figure 4.

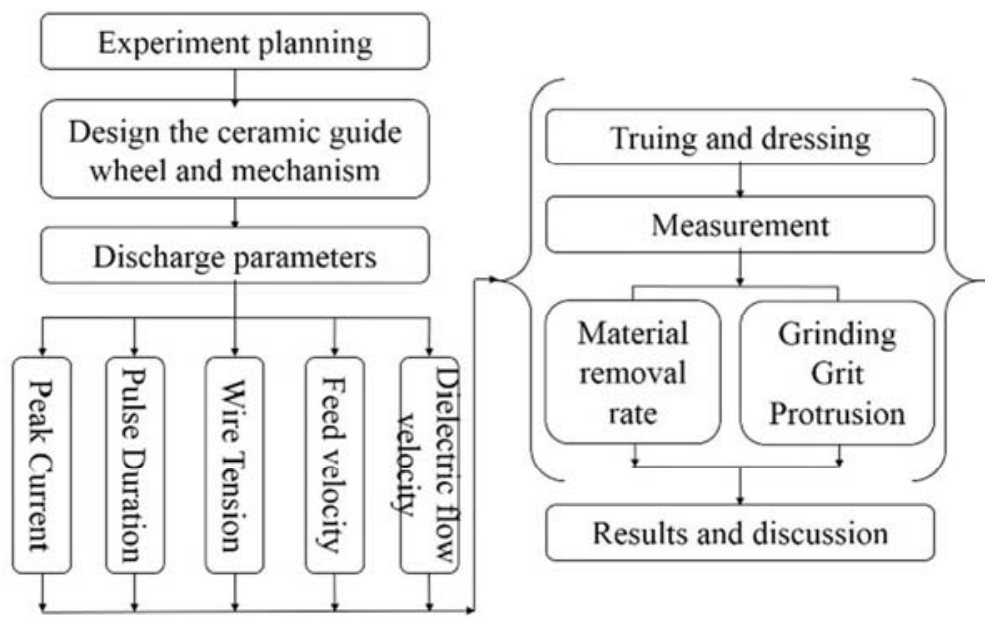

Figure 4. Experimental architecture flowchart.

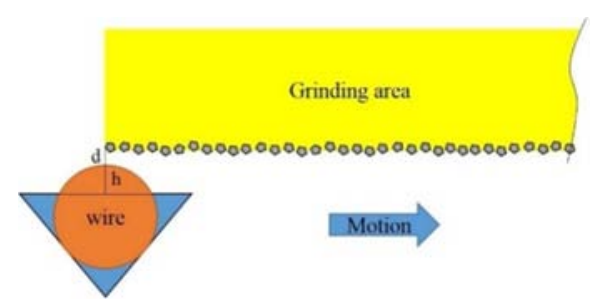

Figure 5. Schematic wire feed mechanism.
The study selected the wire electrode diameter is $0.15 \mathrm{~mm}$, the guide wheel protruding height is $0.043 \mathrm{~mm}$, the discharge gap is $0.02 \mathrm{~mm}$, shown on Figure 5.

\subsection{Taguchi Experimental Design}

The parameters for the discharge current, pulse time, feed rate, liquid flow rate and processing thread tension were selected in this study. The orthogonal array, L18 (35), was applied as shown in Table 1. Group 18 experimental model 
established to calculate the number of mutation and to obtain an optimal combination of discharge parameters. This study has two observation points, respectively, LTB (larger-the-better) characteristic of the material removal rate (MRR) and NTB (nominal-the-better) characteristic of grit protruding amount (Grinding Grit Protrusion, GGP). Since diamond grits binding agent is irregularly distributed, decentralized, so that after each set of experiments to be conducted, the steel block material grinding need to define a new plane during dressing experiment to avoid interference between experiments. Therefore, this study used an average roughness (Ra) and ten point roughness's (Rz) removal rate to calculate the protrusion amount and to find the optimal parameter set and also to conduct Taguchi experimental confirmation runs.

\section{Results and Discussion}

\subsection{Large Diameter Diamond Dressing}

The results showed that the material removal rate is the best Taguchi experimental group, 15 group, the experimental parameters of discharge current 5 Amp, pulse time $30 \mu \mathrm{s}$, feed rate of $1 \mathrm{~mm} / \mathrm{min}$, thread tension $1 \mathrm{~kg}$, working fluid flow rate $0.1 \mathrm{~m} / \mathrm{s}$, in order to accurately measure the amount of abrasive particles projecting. This study was to observe the ten point average roughness third highest peaks and troughs as the distance for the average set of experiments, between two lines of data. Grains protrusion amount of the best Taguchi experimental group for the first 12 groups parameter is discharge current $3 \mathrm{Amp}$, pulse time $30 \mu \mathrm{s}$, feed rate of 0.5 $\mathrm{mm} / \mathrm{min}$, thread tension $3 \mathrm{~kg}$, working fluid velocity $0.1 \mathrm{~m} / \mathrm{s}$.

Figure. 6 shows that the discharge current and pulse rate is proportional to the time and material removal, but the results show a slower feed rate cannot achieve a high material removal rate, while thread tension and flow rate of the processing liquid is not much impact, the experimental parameters for discharge current $5 \mathrm{Amp}$, pulse time $30 \mu \mathrm{s}$, feed rate of $2 \mathrm{~mm} / \mathrm{min}$, thread tension $1 \mathrm{~kg}$, working fluid flow rate $0.05 \mathrm{~m} / \mathrm{s}$. The experimental parameters abrasive grains protrusion amount of the optimal parameter set for discharge current $5 \mathrm{Amp}$, pulse time $20 \mu \mathrm{s}$, feed rate of $1 \mathrm{~mm} / \mathrm{min}$, thread tension $3 \mathrm{~kg}$, working fluid flow rate $0.15 \mathrm{~m} / \mathrm{s}$.

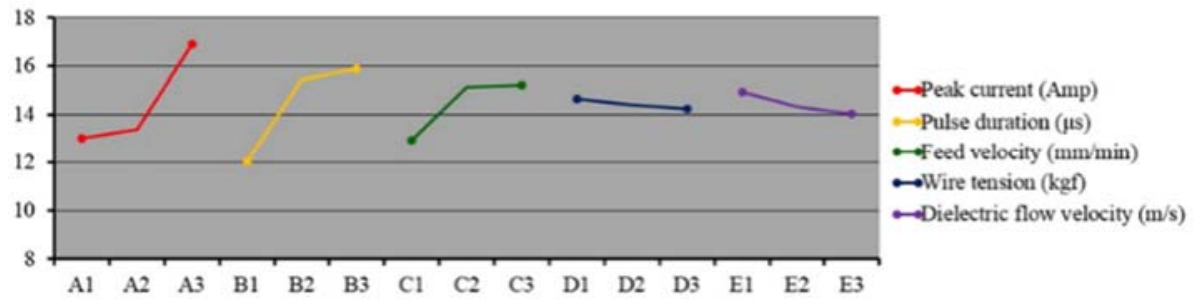

(a)

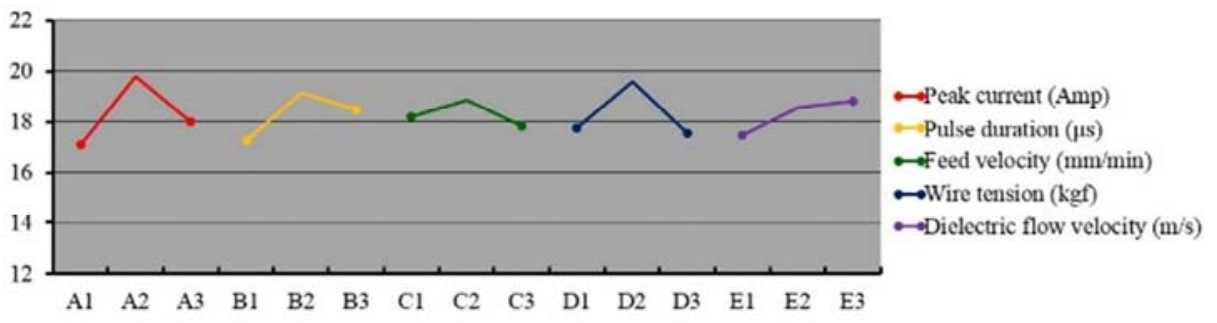

(b)

Figure 6. Response factor larger-diameter wheel (a) MRR (b) GGP.

Table 1 experimental parameters observed 15 groups and the best combination of roughness was $5.488 \mu \mathrm{m}$ and 5.601 $\mu \mathrm{m}$, material removal rates were $11.093 \mathrm{~mm} 3 / \mathrm{min}$ and $11.702 \mathrm{~mm} 3 / \mathrm{min}$, the experimental results of two material removal rate no significant gap, therefore, wire tension and the machining fluid flow rate variation would not have much impact. Hence the study concluded that because of the special guide pulley mechanism can stabilize the wire electrode, the vibration generated by the discharge does not affect the material removal rate, Figure 7 large diameter grinding wheel surface material removal rate curve comparisons. Table 2 and the Taguchi L18 12 Group laboratory in each measurement relatively similar protrusion amount, the maximum protrusion amount were $27.78 \mu \mathrm{m}$ and $33.12 \mu \mathrm{m}$, so the NTB characteristic signal-noise ratio is relatively high, but still cannot reach target value; however, compare the parameters from which we can see the pulse time, the feed rate and the flow rate of the processing liquid abrasive particles may cause damage, resulting in some of the affected grain graphite grains protrusion amount, Figure 8 large particle size abrasive grinding wheel protrusion amount of the surface curve before and after trimming SEM photograph comparison in Figure 9.

Table 1. Large diameter wheel material removal rate optimal quality parameters comparison.

\begin{tabular}{llllll}
\hline Group & $\mathbf{y 1}$ & $\mathbf{y 2}$ & $\mathbf{y 3}$ & $\mathbf{y 4}$ & $\boldsymbol{\eta}$ \\
\hline 15 & 11.10 & 10.87 & 10.78 & 11.08 & 20.90 \\
Optimal & 11.70 & 11.47 & 11.38 & 11.27 & 21.09 \\
\hline
\end{tabular}


Table 2. Large particle size abrasive wheel protrusion amount of the best quality parameters comparison.

\begin{tabular}{llllll}
\hline & $\mathbf{y 1}$ & $\mathbf{y 2}$ & $\mathbf{y 3}$ & $\mathbf{y 4}$ & $\boldsymbol{\eta}$ \\
\hline 12 & 26.21 & 23.59 & 22.54 & 27.78 & 23.05 \\
Optimal & 33.12 & 29.50 & 30.10 & 25.89 & 26.70 \\
\hline
\end{tabular}

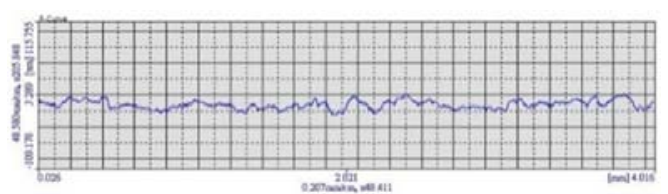

(a)

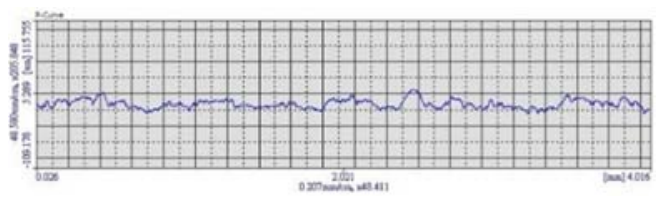

(b)

Figure 7. Large diameter grinding wheel surface material removal rate curve comparison (a) Taguchi group 15 (b) optimal parameter set.

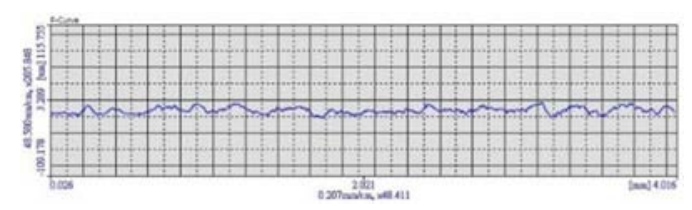

(a)

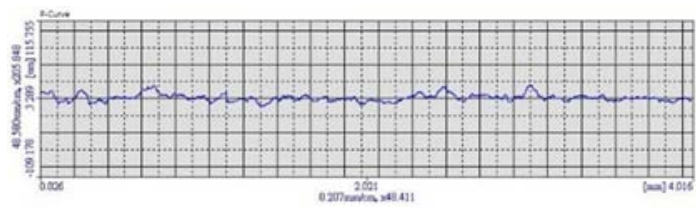

(b)

Figure 8. Large diameter grinding wheel abrasive surface protrusion amount curve comparison (a) Taguchi Group 15 (b) optimal parameter set.

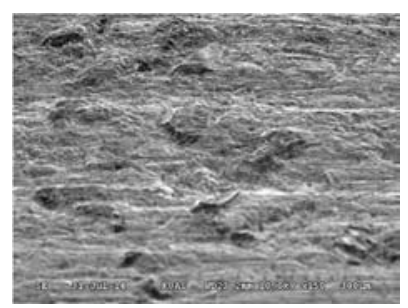

(a)

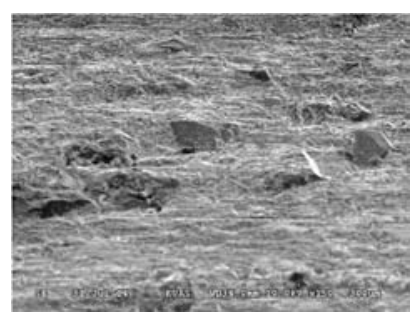

(b)
Figure 9. Large diameter diamond wheel SEM photographs (a) before trimming (b) trimmed.

\subsection{Small Diameter Diamond Dressing}

The results showed that material removal rate is the best Taguchi experimental group that the first group of 18 experimental parameters were discharge current $5 \mathrm{Amp}$, pulse time $30 \mu \mathrm{s}$, feed rate of $1 \mathrm{~mm} / \mathrm{min}$, thread tension $3 \mathrm{~kg}$, dielectric liquid flow rate of $0.05 \mathrm{~m} / \mathrm{s}$. Grains protrusion amount of the best Taguchi experimental group for the first 12 groups parameters were discharge current $3 \mathrm{Amp}$, pulse time $30 \mu \mathrm{s}$, feed rate of $0.5 \mathrm{~mm} / \mathrm{min}$, thread tension $3 \mathrm{~kg}$, working fluid velocity $0.1 \mathrm{~m} / \mathrm{s}$. Figure 10 was the surface roughness of 12 set experiment measurements.

Figure 10 showed the discharge current pulse was proportional to the time and material removal rates, but the results showed that due to the slow feed rate tends to peel off the diamond, resulting in decreasing material removal rate. The optimal experiment parameter set was discharge current 5 Amp, pulse time $30 \mu \mathrm{s}$, feed rate of $2 \mathrm{~mm} / \mathrm{min}$, thread tension $1 \mathrm{~kg}$, working fluid flow rate $0.05 \mathrm{~m} / \mathrm{s}$. Figure 12 was response factor graph of the abrasive protrusion amount, the optimal experiment parameter set for discharge current 5 Amp, pulse time $20 \mu \mathrm{s}$, feed rate of $1 \mathrm{~mm} / \mathrm{min}$, thread tension $3 \mathrm{~kg}$, working fluid flow rate $0.1 \mathrm{~m} / \mathrm{s}$.
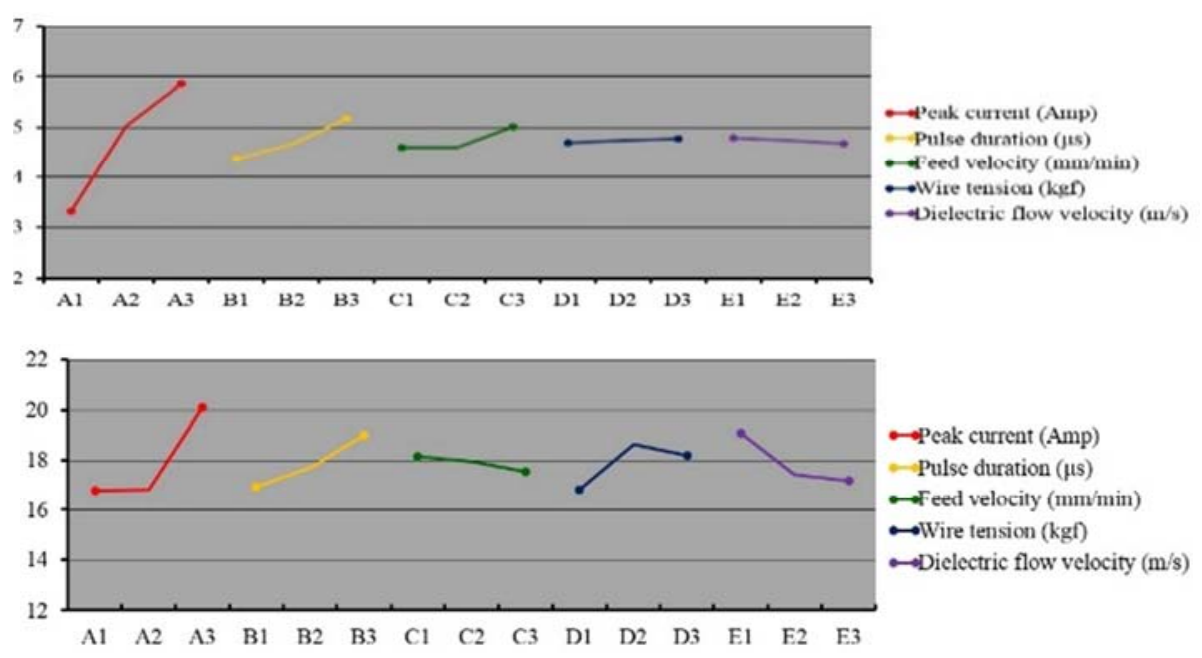

Figure 10. Response factor larger diameter wheel (a) MRR (b) GGP.

Table 3 and Figure 11 could observe 18 groups of experimental parameters and the optimal combination of experimental results. There was no significant difference, in accordance with the theoretical section 4-1 experiments. Due to a smaller particle size, abrasive dense dispersion gap is smaller, so the faster the feed can reduce the contact time per 
unit discharge and often avoid abrasive grains fall off.

Table 3 and 4 in the first set of 12 experiments Taguchi L18 protrusion amount each time measurement is similar, so NTB characteristic signal-noise ratio is relatively high, can achieve the optimal abrasive protrusion amount. However, comparison of the two parameters, a lower current flow rate and faster processing liquid can reach $6.5 \mu \mathrm{m}$, because the faster the flow rate of the machining liquid can be rapidly exclude very small residues, which slow the flow rate and the large current may cause abrasive damage, Figure 12 showed SEM photograph before and after trimming.

Table 3. Small diameter grinding wheel material removal rate optimal quality parameters comparison

\begin{tabular}{llllll}
\hline & $\mathbf{y 1}$ & $\mathbf{y 2}$ & $\mathbf{y 3}$ & $\mathbf{y 4}$ & $\boldsymbol{\eta}$ \\
\hline 18 & 1.97 & 1.98 & 2.14 & 2.13 & 6.24 \\
Optimal & 1.97 & 1.96 & 2.16 & 2.17 & 6.27 \\
\hline
\end{tabular}

Table 4. Small particle abrasive grinding wheel protrusion amount of optimal quality parameters comparison.

\begin{tabular}{llllll}
\hline & $\mathbf{y 1}$ & $\mathbf{y 2}$ & $\mathbf{y 3}$ & $\mathbf{y 4}$ & $\boldsymbol{\eta}$ \\
\hline 12 & 7.53 & 6.56 & 6.56 & 6.80 & 23.47 \\
Optimal & 6.56 & 5.83 & 5.83 & 6.56 & 23.35 \\
\hline
\end{tabular}

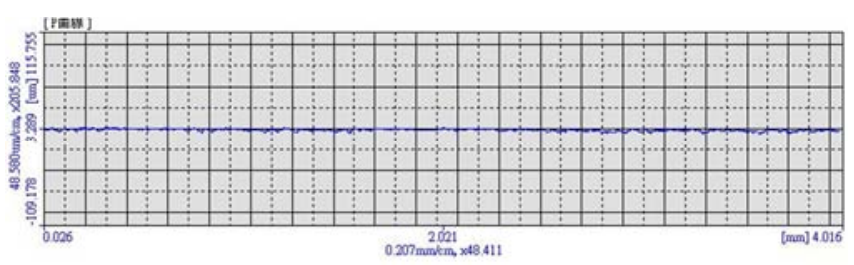

(a)

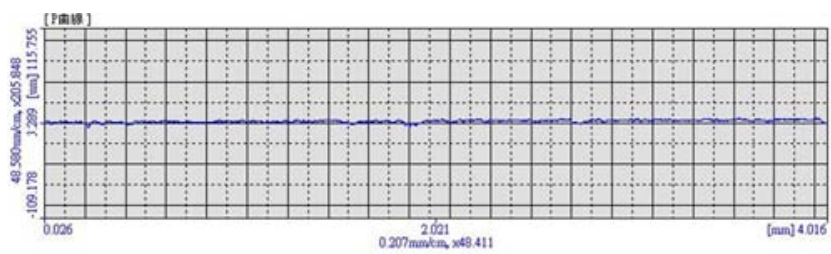

(b)

Figure 11. Small diameter grinding wheel abrasive surface protrusion amount curve comparison (a) Taguchi Group 18 (b) optimal parameter set.

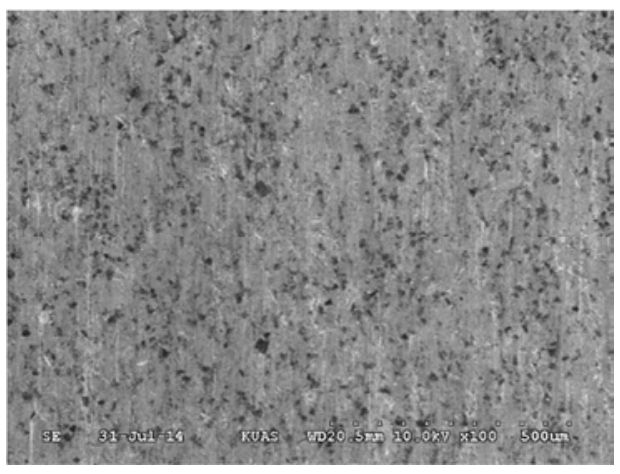

(a)

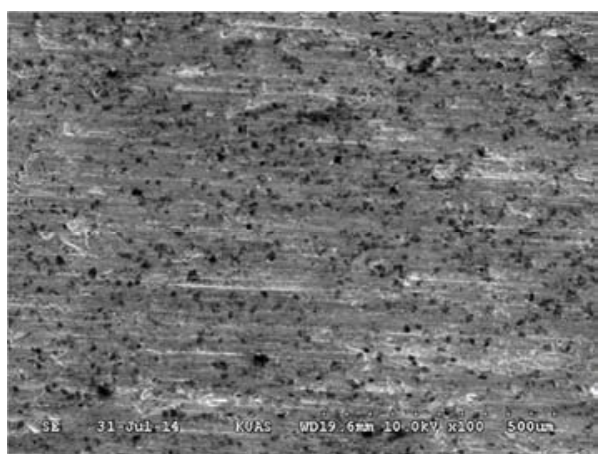

(b)

Figure 12. Small diameter diamond wheel SEM photograph (a) before trimming (b) trimmed.

\section{Conclusions}

(1) The successful research techniques to WEDD metal matrix diamond grinding wheel dressing, changes in the material removal rate is small, the mechanical error caused by changes in the value exceeds, summarized the reasons for the error caused by process variation of the machinery, and the error noise interference are external factors, not easy control, but still experimentally sorted out from the discharge current and pulse time for the effect of material removal rate and the abrasive grains protrusion amount.

(2) From the Taguchi experiment variance analysis, the contribution of the discharge current to influence the material removal rate was maximum, its value was $42.52 \%$, followed by the pulse time contribution of $39.86 \%$, while the contribution representing the thread tension was small, the reason was greater current increasing greater energy, and greater energy leading to greater volume of material removed; but the energy easily lead to damage the diamond, and pulse duration was the same.

(3) The experimental results showed no matter how big or small particle diameter of the wheel, and the contribution of the discharge current pulse time was larger. However, a small particle size relative to the large diameter of the wheel, because the spacing between the abrasive particle size was large, easy to remove residual material after discharge, and small diameter grinding wheel due to the material removal rate was too large and leaving diamonds peeling.

(4) Experimental small diameter grinding wheel stone material removal rate with the maximum contribution of pulse time, followed by the discharge current, the thread tension is less significant; likewise protrusion amount of grain, but the contribution is small compared to the feed rate.

(5) Taguchi method results showed, the larger-diameter diamond grinding wheel in terms of the following two best discharge parameters set, the material removal rate was the best combination of parameters discharge current 5 Amp, pulse time $30 \mu \mathrm{s}$, the feed rate of $2 \mathrm{~mm} / \mathrm{min}$, wire tension is $1 \mathrm{kgf}$, machining fluid flow rate $0.05 \mathrm{~m} / \mathrm{s}$. Grains protrusion amount compared with the discharge current $5 \mathrm{Amp}$, pulse time $20 \mu \mathrm{s}$, feed rate of $1 \mathrm{~mm} / \mathrm{min}$, thread tension $3 \mathrm{kgf}$, machining fluid flow rate $0.15 \mathrm{~m} / \mathrm{s}$. 
(6) In terms of the smaller-diameter diamond wheel to get the optimal combination of experimental parameters: optimum material removal rate parameter combination discharge current $5 \mathrm{Amp}$, pulse time $30 \mu \mathrm{s}$, feed rate of 0.5 $\mathrm{mm} / \mathrm{min}$, thread tension $5 \mathrm{kgf}$, machining fluid flow rate 0.1 $\mathrm{m} / \mathrm{s}$; abrasive protrusion amount of the discharge current 3 Amp, pulse time $30 \mu \mathrm{s}$, feed rate of $0.5 \mathrm{~mm} / \mathrm{min}$, thread tension $3 \mathrm{kgf}$, machining fluid flow rate $0.1 \mathrm{~m} / \mathrm{s}$.

\section{Acknowledgements}

Thanks NSC NSC 102-2221-E-252-003-MY2 subsidy project, so that the study can be completed more smoothly, thanks to Professor Wang Min-Wen Kaohsiung University of Applied Science and Technology, Metal Industries Research and Development Center Dr. Zeng Jun jie provided valuable opinions, so that the paper can be improved. In the course of the study, thanks to China Mr. Wang armor in the production of diamond grinding wheel provided opinions in each wheel and Mr. Sheng Wang Xin jie industrial companies provide ceramic guide wheel making comments in order to complete the experiments timely.

\section{References}

[1] Srivastava, U. Mayank, 2013, "Review of Dressing and Truing Operations for Grinding Wheels," International Journal of Engineering Science, Vol. 5, No. 1, ISSN: 0975-5462.

[2] E. Weingärtner, S. Jaumann, F. Kuster, and M. Boccadoro, 2010, "Special Wire Guide for On-Machine Wire Electrical Discharge Dressing of Metal Bonded Grinding Wheels," CIRP Annals-Manufacturing Technology, Vol. 59, Issue 1, pp. 227-230.

[3] C. Zhang and Y. C. Shin, 2002, "A novel laser-assisted truing and dressing technique for vitrified CBN wheels," International Journal of Machine Tools and Manufacture, Vol. 42, Issue 7, pp. 825-835.

[4] A. Hosokawa, T. Ueda and T. Yunoki, 2006, "Laser dressing of metal bonded diamond wheel," CIRP Annals-Manufacturing Technology, Vol. 55, Issue 1, pp. 329-332.

[5] H. Ohmori, Y. Dai, W. Lin, T. Suzuki, K. Katahira, N. Itoh, A. Makinouchi and H. Tashiro, 2002, "Force characteristics and deformation behaviors of sintered $\mathrm{SiC}$ during an ELID grinding process," Advances in Abrasive Technology, Vol.238-239, Issue 5, pp. 65-70.

[6] J. Xie, H. F. Xie, M. J. Luo, T. W. Tan, and P. Li, 2012, "Dry Electro-Contact Discharge Mutual-Wear Truing of Micro Diamond Wheel V-ip for Precision micro-Grinding," International Journal of Machine Tools and Manufacture, Vol. 60, pp. 44-51.

[7] E. Weingärtner, S. Jaumann, F. Kuster and K. Wegener, 2010, "On-Machine Wire Electrical Discharge Dressing (WEDD) of Metal-Bonded Grinding Wheels," The International Journal of Advanced Manufacturing Technology, Vol. 49, Issue 9-12, pp. 1001-1007.

[8] K. Wegener, E. Weingärtner and M. Blaser, 2013, "In-Process Wire Electrical Discharge Dressing (IWEDD) of Metal Bonded Diamond Wheels," CIRP Annals-Manufacturing Technology, Vol. 62, Issue 1, pp. 339-342.

[9] A. Sudiarso and J. Atkinson, 2008, "In-Process Electrical Dressing of Metal-Bonded Diamond Grinding Wheels," Engineering Letters, Vol. 16, Issue 3, pp. 308-310.

[10] H. Ohmori, K. Katahira, W. Lin, Y. Dai, T. Suzuki and N. Itoh, 2002, "Nano-precision Surface Machining for Ceramics by Ultraprecision ELID-Grinding," CERAMICS JAPAN, Vol. 37, Issue 10, pp. 799-802.

[11] H. K. Tonshoff and T. Friemuth, 2000, "In-process dressing of fine diamond wheels for tool grinding," Precision engineering, Vol. 24 Issue 1, pp. 58-61

[12] T. S. Kwak, Y. C. Lee, G. N. Kim, D. B. Choi, M. Yamanoi and H. Ohmori, 2009, "Nano-Precision Combined Process of Electrolytic In-Process Dressing Grinding and Magnetic Assisted Polishing on Optics Glass Material," Transactions of Nonferrous Metals Society of China, Vol. 19, pp. s301-s306.

[13] M. H. Raffles, D. J. Stephenson, P. Shore and T. Jin, 2011, "Electrolytic In-Process Dressing Superfinishing of Spherical Bearings Using Metal-Resin Bond Ultra-Fine CBN Wheels," Proceedings of the Institution of Mechanical Engineers, Part B: Journal of Engineering Manufacture, Vol. 225, Issue 1, pp. 112-122.

[14] A. M. Shanawaz, S. Sundaram, U. T. S. Pillai, andP. B. Aurtherson, 2011, "Grinding of Aluminium Silicon Carbide Metal Matrix Composite Materials by Electrolytic In-Process Dressing Grinding," The International Journal of Advanced Manufacturing Technology, Vol. 57, Issue 1-4, pp. 143-150. 